\title{
An Identification of Conceptual and Procedural Understanding: Study on Preservice Secondary Mathematics Teacher
}

\author{
Kondradus Yohanes Klau', Meiva Marthaulina Lestari Siahaan ${ }^{2 *}$, Justin E. Simarmata ${ }^{3}$ \\ 1,2,3 Universitas Timor, Indonesia
}

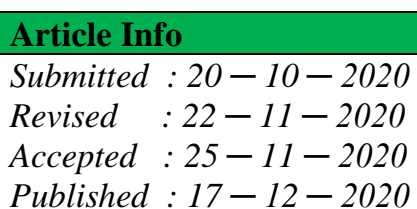

*Correspondence: meivamarthaulina@unimor.ac.id

\begin{abstract}
Preservice mathematics teachers (PSMTs) need to master teaching material besides pedagogical competence. This knowledge is a combination of conceptual and procedural knowledge. Teachers should possess the ability to explain a concept, the reason for the concepts used, and the relationship among several concepts clearly and effectively to identify why the concept is used. This study aimed to identify the conceptual and procedural knowledge of PSMTs in Linear Algebra courses. Data collection was carried out through tests and interviews. The interview was conducted with several participants to clarify their test answers. The participants' interview answers revealed that they had difficulty in choosing the proper concept answering modified questions. Also, the participants tried to answer the question using a procedural approach. According to the findings, it is vital to construct appropriate teaching materials appropriate for the learning objective and material map concept.
\end{abstract}

Keywords: Conceptual Understanding; Preservice Mathematics Teacher; Procedural Understanding; Vectors

http://ejournal.radenintan.ac.id/index.php/al-jabar/index

Preservice mathematics teachers (PSMTs) learned elementary linear algebra as an abstract course in the first semester. This course is expected to be a basic skill for PSMTs to teach algebra in high schools. Content knowledge and pedagogical competencies affect the learning and teaching environment due to the teacher's important role in using different styles of representation in the classroom (Dündar, 2015).

Universities should be credible institutions to produce highly competent teachers who master the subject material knowledge (SMK). Mathematics education courses taken by preservice teachers influence their knowledge development and improvement (Chen, Dooren, Chen, \& Verschaffel, 2011; Crespo, 2003). The researchers have found that insufficient SMK among teachers led their students to develop misconceptions, misunderstandings, and misinterpretations regarding the subject matter (Valanides, 2000).

Several learning theories state that different types of knowledge form learning behavior as an outcome. An abstract understanding of a theory or principle from a specific knowledge in a particular domain is used to quickly and precisely solve a problem (Schneider, Michael \& Stern, Elisabeth, 2015).

Knowledge material is required for mathematics teachers to be competent and effective in teaching based on the course knowledge, which combines knowledge concepts and procedures. Rittle-Johnson \& Schneider (2012) stated that two-way interactions are the relationship between the two types of knowledge. Ideally, mathematics teachers are expected to show knowledge of concepts and procedures. 
Competence in the Linear Algebra course requires conceptual and procedural knowledge in interpreting a problem. Star, Caronongan, Furgeson, Keating, Larson, Lyskawa, McCallum, Porah, and Zbiek (2015) state that there is a difference between students who use mnemonics to answer the multiplication result of $(a+b)(x+y)$ with students who can explain where the mnemonic comes from.

PSMTs must know what and why they are thinking about. These knowledge skills are summarized in conceptual and procedural knowledge. This is in line with Badjeber and Mailili (2019) statement that students who understand conceptual knowledge well in a topic will know the connection between principles and concepts that provide reasons to explain some facts as a consequence of other facts.

There are two basic and complete knowledge of mathematics that every student must master. The first is knowledge related to mechanical data, such as recognizing symbols and performing operations. Another knowledge is the ability to place symbols on mathematical concepts, make connections, and do operations appropriately (Baki, 2008).

Gaining insight from the learned knowledge can provide basic skills to generate new knowledge and solve problems (National Research Council, 2001). Able to memorize the mathematical rules, definitions or procedures does not imply having conceptual knowledge. The ability to explain the rules, definitions, or procedures is needed to prove the conceptual knowledge. Besides, conceptual knowledge involves understanding meaning, not just the ability to recall definitions, rules, or procedures.

Certain types of problems are not only describing something (Rittle-Johnson \& Schneider, 2012), but they can also be explicit or implicit because they are not written. Kilpatrick, Swafford, and Findell (2001) named this knowledge as understanding mathematical concepts, operations, and relationships. Schneider and Stern (2010) showed that conceptual knowledge provides an abstract understanding of the principles and relationships between particular domains. This theory was strengthened by Khashan (2014), who defined conceptual knowledge as abstract knowledge that describes the essence of mathematical principles and the relationships between them.

The ability to memorize either mathematical principles, definitions, or procedures and apply them does not imply having conceptual knowledge. A person's ability to explain the principles, definitions, or procedures is needed to prove that they have conceptual knowledge. Concept knowledge involves understanding meaning, not just the ability to recall definitions, rules, or procedures. Khashan (2014) strengthens this definition by stating that conceptual knowledge, as abstract knowledge, describes the essence of mathematical principles and their relationships.

Furthermore, Isleyen and Isik (2003) described conceptual knowledge in mathematics as knowledge consisting of symbols and demonstrations. Therefore, conceptual knowledge represents mathematical concepts and connects mathematical knowledge to a complete understanding of mathematical concepts, rules, and propositions. Therefore, conceptual knowledge in mathematics helps understand the relationship between mathematical concepts, definitions, and rules. These relationships can provide what has been stated. In other words, conceptual knowledge in mathematics explains why and how the procedures are necessary for logical and correct solutions to mathematical problems.

Sleyen and Isik (2003) described procedural knowledge as knowing the procedures, rules, and algorithms to solve mathematical problems. This description described knowledge as 
mechanical because it does not include conceptual understanding. This is why Heibert and Lefevre (1986) stated that procedural knowledge is meaningful because it is linked to a conceptual basis due to the solid basis for implementing a procedure that lies in the concept. Khashan (2014) defined procedural knowledge as the ability to explain or justify how a person solves a problem without knowing the reasons behind applying specific theories, processes, or laws during the problem-solving process.

Rittle-Johnson \& Schneider (2012) defined procedural knowledge as knowing the needed procedures to achieve various goals. Procedural knowledge shows the use of rules, algorithms, or procedures in the form of a relevant representation. This knowledge requires understanding the objects and the format and syntax for expressing outlined representation (Kadijevich, 2018).

In this study, procedural knowledge is the ability to memorize the rules, procedures, principles, and definitions of mathematics in solving problems. According to Verschaffel et al. (2009), the procedural ability can be directly assessed from the ability to solve problems in more than one way and choose the most relevant procedure to solve a problem.

This study is critical because it would be a base for educators to understand the way of thinking and the trajectory of PSMTs. Furthermore, the identification result would produce literature relevant to PSMTs characteristics.

Based on the description, the indicators of conceptual understanding used in this study (Badjeber and Mailili, 2019) were interpreting models, symbols, signs, or terms used to represent concepts, manipulating related ideas using various kinds of representations, and identifying principles related to problems in vectors. Also, the indicators of procedural ability used in this study were (Iswanly, Pomalato, \& Djabar, 2018) knowledge of procedures in general, knowledge of when and how to use procedures correctly, knowledge in performing procedures flexibly, precisely, and efficiently.

\section{The Research Methods}

The participants of this study were PSMTs who took Elementary Linear Algebra and Linear Algebra course in the academic year 2020/2021. This study was qualitative. The research approach was analyzing the participants in taking tests of conceptual and procedural understanding. The data analysis techniques were data selection (reduction), data presentation, and data verification by double-checking the data and drawing conclusions (Komarudin, 2016). The data tabulation technique was used to analyze participants' answers and interview results.

\section{Research Instruments}

The data was collected using a conceptual and procedural understanding test by adapting the vector topic handbook. This test aimed to analyze the PSMTs' conceptual and procedural knowledge. The following table displays the instrument.

Table 1. Research instrument

\begin{tabular}{clc} 
Item & \multicolumn{1}{c}{ Instrument Specification } & \multicolumn{1}{c}{ Instrument } \\
\hline 1 & Interpret the form of $\|p\|,\|q\|,\|p\|+$ & Example $p=(1,-3,2), q=(1,1,0)$, \\
& $\|q\|$, and $\|p+q\|$ and manipulate the & and $r=(2,2,-4)$, answer the \\
representation of $\|p\|+\|q\|$ and & question below: \\
& $\|p+q\|$ to identify the rules related to & a. $\|p\|+\|q\|$ \\
& vector problems. After the PSMTs can & b. $\|p+q\|$ \\
& interpret these forms, they can solve & \\
& problems by understanding what, & \\
\hline
\end{tabular}




\begin{tabular}{|c|c|c|}
\hline & $\begin{array}{l}\text { when, and how these procedures are } \\
\text { used appropriately. }\end{array}$ & \\
\hline 2 & $\begin{array}{l}\text { Determine the coordinates of a point if } \\
\text { the portion of a vector is known. }\end{array}$ & $\begin{array}{l}\text { Point } \mathrm{P} \text { is } 1,7 \text {, and point } \mathrm{Q} \text { is } 4,1 . \text { Point } \\
\mathrm{R} \text { is a point on a connecting line } \mathrm{PQ} \\
\text { that } \overrightarrow{P R}=\frac{1}{3} \overrightarrow{P Q} . \text { So, the point of the } \mathrm{R} \\
\text { coordinate is? }\end{array}$ \\
\hline 3 & $\begin{array}{l}\text { Find the value of } \tan \theta \text { from the two } \\
\text { adjacent vectors. }\end{array}$ & $\begin{array}{l}\text { If } \overrightarrow{O A}=(1,2), \overrightarrow{O B}=(4,2), \text { and } \theta= \\
\angle(\overrightarrow{O A}, \overrightarrow{O B}), \text { then } \tan \theta \text { is? }\end{array}$ \\
\hline 4 & $\begin{array}{l}\text { Interpret the geometric representation } \\
\text { of vector addition. }\end{array}$ & $\begin{array}{l}\text { The image below shows that... } a+ \\
b+c=\end{array}$ \\
\hline
\end{tabular}

\section{The Results of the Research and the Discussion}

The results from 151 participants were divided into several types of responses and percentages in each instrument item. This section covers the results of data reduction and data presentation.

\section{Item 1}

The participants were expected to interpret, manipulate, and identify symbols $\|p\|,\|q\|$, and $\|p+q\|$ due to the different representation between $\|p\|,\|q\|$, and $\|p+q\|$. Then the participants were able to use the symbol correctly. This means that they could use the rules of number operation correctly.

Table 2. The classification of Participants' Responses

\begin{tabular}{clc} 
No & \multicolumn{1}{c}{ Classification of Participants' Responses } & Percentage \\
\hline a & Work by fulfilling all the indicators of conceptual & $21.85 \%$ \\
& understanding and procedures & \\
b & Interpretation into the several concepts & $78.14 \%$ \\
c & No answer & $0.013 \%$ \\
\hline
\end{tabular}

The classification of participants' response (CPR) on item 1part b (CPR 1.b) was varied.

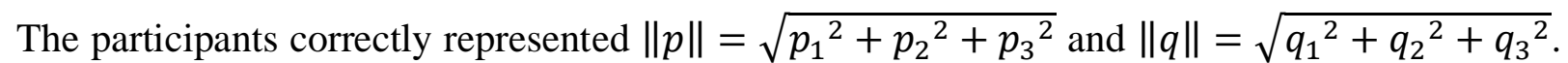
However, the participants failed to represent the form of $\|p+q\|$. One of the variations of CPR 1.b is $\|p\|+\|q\|=\|p+q\|$. In this variation, the participants made an exact definition and process of completion in both forms. This variation is the most widely used by participants in CPR 1.b.

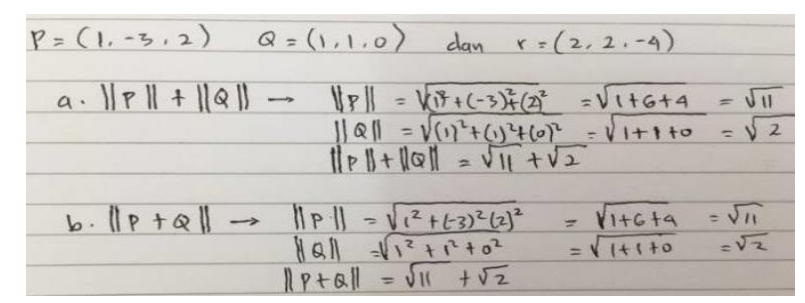

Figure 1. The Representation of CPR 1.b.(i) 
The excerpt of the interview on CPR 1.b. is as follows:

Researcher: If we want to find the value of $p$, which one should we use?

Participant: This one, Ma'am (while pointing his answer)

Researcher: Good. What do you think about the part a and b question? Were they the same?

Participant: They were different, Ma'am. Part a is separated while part b is combined (addition of $a$ and $b$ values).

Researcher: Why did you define a and $\mathrm{b}$ as the same if they had different forms?

Participant: According to the formula, the results were the same.

Based on the interview results, the participant could state different forms of part a and part b. However, in the process, he interpreted that parts a and part b were the same. There were inconsistencies. It was suspected that the participant was accustomed to completing part a of the problem; thus, he did not know how to solve part b.

Section (ii) defined $\|p+q\|=\sqrt{\left(p_{1}+q_{1}\right)^{2}+\left(p_{2}+q_{2}\right)^{2}+\left(p_{3}+q_{3}\right)^{2}}$ and section (iii) defined $\|p+q\|=\sqrt{\left(p_{1}-q_{1}\right)^{2}+\left(p_{2}-q_{2}\right)^{2}+\left(p_{3}-q_{3}\right)^{2}}$. The Interview results of CPR 1.b. (ii) are as follow:

Researcher: Why did you answer question 1 part b like this?

Participant: Because the question was $p+q$. Since they were combined, I multiplied them. I added part a because they were separated.

Based on the above interview results, the participants had no basis at all regarding the concepts. They tried to make an analogy according to their interpretation of a form.

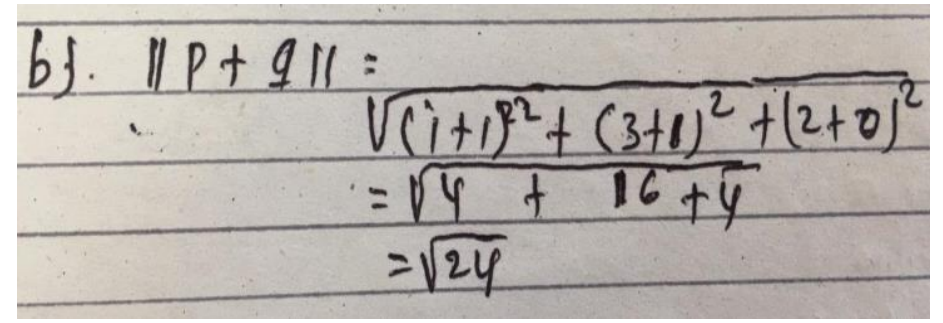

Figure 2. The Representation of CPR 1.b.(ii)

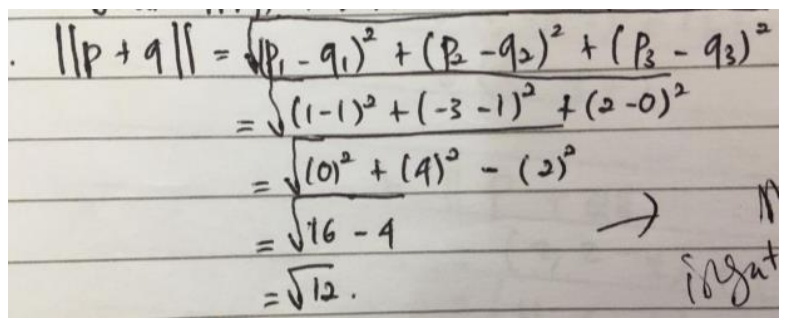

Figure 3. The Representation of CPR 1.b.(iii)

The following are the results of the interview on PCR 1.b. (iii):

Researcher: Okay, when you look at the value of P + Q, you found it by subtracting the two vectors? For part a, finding the value of p plus q, you added the two vectors. 
Participant: I remembered the distance formula material, and its form was similar, so I wrote it like that.

Based on the interview results, the participants did not understand the basic concept of the value of a vector. The participant encountered a problem in finding the value of a single vector. In contrast, when the participant faced finding the value of additional vectors, he looked for other similar forms.

\section{Item 2}

Item 2 expected the participants to understand the concept of point coordinates, vector portions, and vector relationships with lines.

Table 3. The Classification of Participants' Response on Item 2

\begin{tabular}{llc} 
No & Classification of Participants' Response & Percentage \\
\hline A & Work by fulfilling all indicators of conceptual & $1.32 \%$ \\
& and procedural understanding & \\
b & Interpretation into the several concepts & $52.31 \%$ \\
c & No answer & $46.37 \%$ \\
\hline
\end{tabular}

Some variations for CPR 2.b were (i) finding the quantity of each vector, (ii) using the distance formula, (iii) interpreting the coordinate plane.

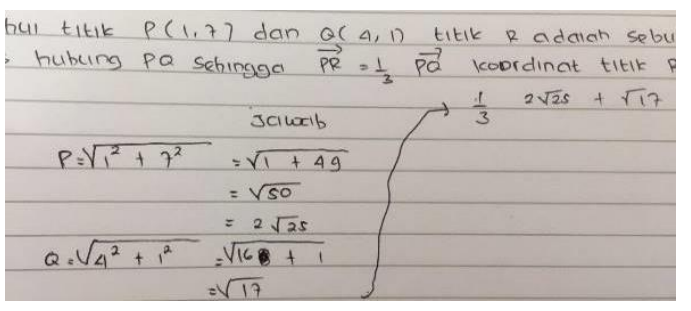

Figure 4. The Representation of CPR 2.b.(i)

The interview results of CPR 2.b.(i)are as follow:

Researcher: You were told to find the coordinate point, right? I wonder why did you start by looking for the quantity?

Participant: I looked for the $\mathrm{p}$ and q quantity first, then I input in the PR, one-third of the PQ. So, I made one-third P plus Q

The participant stated that PQ is relevant to $\|P\|+\|Q\|$, so that the quantity must be found first. The participants did not fully understand the concept of vectors and even the form of the coordinate points.

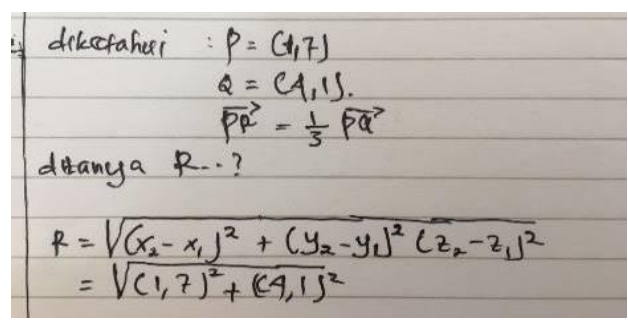

Figure 5. The Representation of CPR 2.b.(ii) 
The interview results of CPR 2.b.(ii) are as follow:

Researcher: From the formula you wrote, can you get the coordinate point R? What exactly is this formula?

Participant: I have two points, Ma'am. I subtracted them to get the point R.

Researcher: You know what formula was this?

Participant: I do not know, Ma'am.

Researcher: Why did you use this?

Participant: I used it because I got a similar question, Ma'am.

Based on the interview, the participant tried to remember what she had done before by identifying similarities and then making an analogy that they were similar. She used the distance formula even though she did not know what it was.

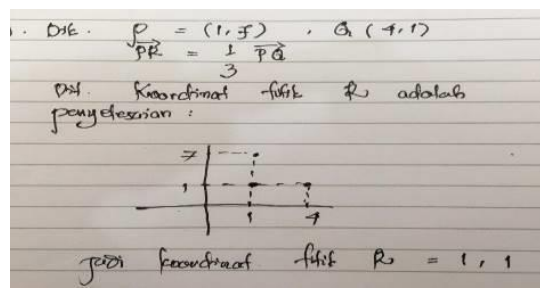

Figure 6. The Representation of CPR 2.b.(iii)

The interview results on CPR 2.b (iii) are as follow:

Researcher: The coordinate point $\mathrm{R}$ was questioned, then why you answered it like this?

Participant: To get the point $\mathrm{R}, \mathrm{I}$ had to pass the points $\mathrm{P}$ and $\mathrm{Q}$.

Based on the interview, the participants thought that by making a point $(1,1)$, it would become a point between $\mathrm{P}$ and $\mathrm{Q}$, and the coordinates $(1,7)$ and $(4,1)$ could also be passed. Here, the participant tried to make the shortest distance from the two vectors even though he did not know that it was useless. The participants experienced misconceptions about the concept of coordinates and distance.

\section{Item 3}

Item 3 expected the participants to use the cosine relationship with scalar multiplication and vector magnitude multiplication and then find the values using trigonometric rules.

Table 4. The Classification of Participants' responses

\begin{tabular}{llc} 
No & \multicolumn{1}{c}{ Classification of participant response } & Percentage \\
A & $\begin{array}{l}\text { Work by fulfilling all indicators of conceptual } \\
\text { and procedural understanding }\end{array}$ & $2.65 \%$ \\
B & Interpretation into several concepts & $77.53 \%$ \\
C & No answer & $19.82 \%$ \\
\hline
\end{tabular}

CPR 3.b consisted of several variations, namely (i) assumed $\cos \theta=\tan \theta$, (ii) Formed $\tan \theta=\frac{d e}{s a}=\frac{\overline{O B}}{\overline{O A}}$, and (iii) Found $\overline{A B}$ 


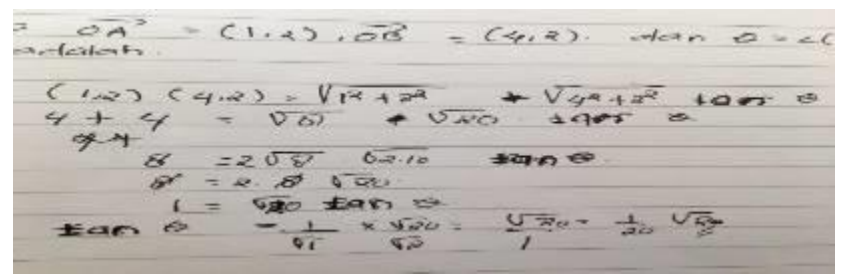

Figure 7. The Representation of CPR 3.b. (i)

The interview results of CPR 3.b. (i) are as follow:

Researcher: You have to find the value of $\tan \theta$. Is this the exact way to find the $\tan \theta$ ?

Participant: Yes, this is the exact formula, Ma'am.

Researcher: Is this because you did not know that you wrote it this way?

Participant: I thought that this was the correct formula, Ma'am.

Based on the interview results, the participant was very confident in their answers. This showed that he did not receive the information as a whole. This is a dangerous misconception where the participants strongly believe incorrect concepts.

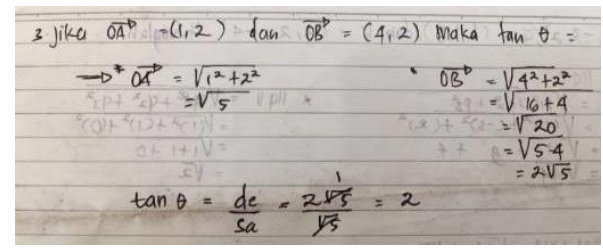

Figure 8. The Representation of CPR 3.b (ii)

The interview results of CPR 3.b.(ii) are as follow:

Researcher: Why did you make $\tan \theta$ like this?

Participant: Actually, I knew that I had to find $\cos \theta$ first, but I did not remember the formula. So, I directly searched for $\tan \theta$.

Based on the interview, the participants knew that to find the value oftan $\theta$, they had to find $\cos \theta$ first. It can be seen that they did not understand the concept of an angle between the two vectors. Also, the fact that the dot product produced scalars was ignored.

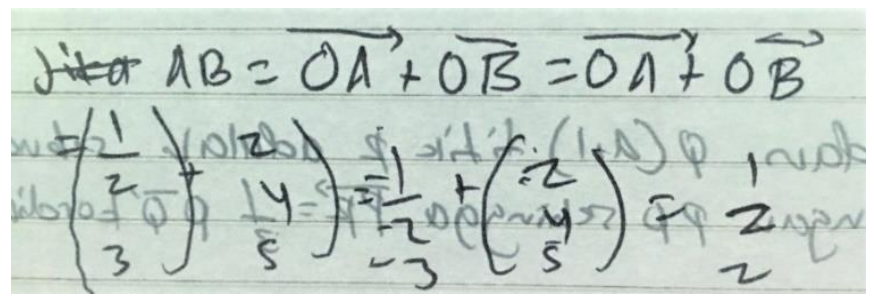

Figure 9. The Representation of CPR 3.b. (iii)

The interview results of CPR 3.b.(iii) are as follow:

Researcher: You have to find the value of $\tan \theta$, then why did you look for the $\mathrm{AB}$ like this?

Participant: Because the $\mathrm{AB}$ consisted of $\mathrm{OA}$ and $\mathrm{OB}$, so I added them. Then, I looked for $\tan \mathrm{AB}$, but I did not have the time to do it. 
The participants did not understand that the tangent value they were looking for had to be a quantity, not a vector. It reached the point that an angle was flanked by both vectors OA and $\mathrm{OB}$ but failed to define the value of $\tan \mathrm{AB}$.

\section{Item 4}

Item 4 expected the participant to understand the representation of vector addition, show vector resultants, and understand algebraic calculations as the implications of vector addition.

Tabel 5. The Classification of Participants' Response

\begin{tabular}{clc}
\hline No & \multicolumn{1}{c}{ Participant Response Type } & Percentage \\
A & $\begin{array}{l}\text { Worked by fulfilling all indicators of } \\
\text { conceptual and procedural understanding }\end{array}$ & $0 \%$ \\
B & Interpretation into several concepts & $61.56 \%$ \\
C & No answer & $38.44 \%$ \\
\hline
\end{tabular}

According to the classification of response in item 4, there were no participants who could work with the vector addition concept and procedure correctly. At least, the participants could define the resultant vector.

CPR 4.b had several variations, namely (i) create a vector representation with coordinate points. A participant described the vector and gave it a coordinate point in R3 even though there was no problem that the vector was located in R3. This needed to be clarified to the participants why they made the coordinates of such a point.

The next variation was (ii) defining the vector addition without processing. Three participants could define the vector addition in the image but they could not define $a+b+c$. The rest of the participants directly wrote their answers without defining the resultant of the available vector images. Various participants' definitions were (1) $a+b+c=\bar{A}-\bar{B}+\bar{C}$, (2) $a+b+c=a b c$, (3) $a+b+c=\sqrt{a^{2}+b^{2}+c^{2}}$, (4) $a+b+c=a b=b c$, (5) $a+b+c=$ $a c$, (6) $a+b+c=a b+b c+a c$, (7) $a=\frac{b}{c}, b=a . c$, (8) $b=a+c$, (9) $a+b=-c$, (10) $2 a+2 b$, (11) $b-c$, (12) $b+a+c$, (13) $a-c$.

The last variation of CPR 4.b was (iii) the participant did not define the vector addition. The definition consisted of (1) vector addition using the triangle method, (2) vectors having values and directions, (3) unidirectional vectors, (4) multiplication on vectors, (5) $a+b+c$ is a constant, and (6) resultant vector $=b$.

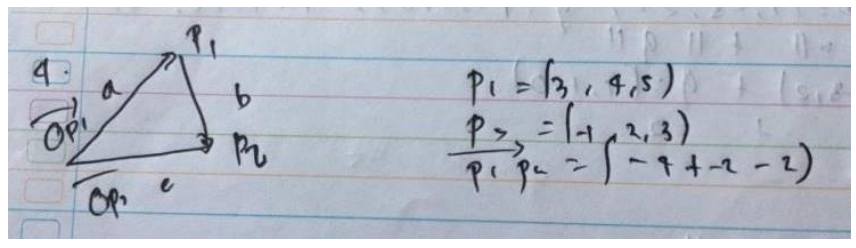

Figure 10. The Representation of CPR 4.b. (i)

Interview result with participant code CPR 4.b.(i)

Researcher: In your paper, you are supposed to point the $\mathrm{O}, \mathrm{P}_{1}$, and $\mathrm{P}_{2}$, then each of those had a coordinate point. Why did you write it that way?

Participant: I was reminded of the Geometry course, which provided an example like the one in this picture, so I named the points $\mathrm{O}, \mathrm{P} 1$, and P2. I assumed the 
coordinates and found the results because it could not be searched if there were no numbers.

Based on the interview results, the participants made an example by providing the coordinates of each vector. They tried to make the problems into a concrete form so that they can find a solution.

According to the answers and data reduction, the participants' responses belong to the "Interpretation into several concepts" category. This response type is related to the conceptual knowledge indicators part (2), namely manipulating related ideas using various kinds of representations. Unfortunately, the participants' ideas were not relevant to the problem given. According to Smith and Smith (2006), conceptual understanding is more than just memorization and correct answer.

There are several results based on reduction data, interviews, and literature review in this study. The first claim was that the participants had difficulty in choosing the right concept and applying the procedure. It can be seen in item 1 part $b$, where the participants inconsistently represented forms $\|p+q\|$. Also, many participants defined and applied procedural steps in part a. it seems that they had incomplete information. This was closely related to the assimilation and accommodation thought processes.

There is a process between the incoming information and the schema (cognitive structure) in the human brain. New experiences or information will be processed through the process of assimilation or accommodation (Kurniawan, Mulyati, \& Rahardjo, 2017). Participants' various experiences and information should be remembered, so they can be recalled when a problem is presented. However, there was a calling failure.

The second result was that the participants seemed to be familiar with routine questions. Routine questions usually include applying a similar mathematical procedure to question recently learned (Putri, 2018). In item 3, the participants were told to find the value of $\cos \theta$. However, most of the participants wrote the $\tan \theta$ formula due to the habit of doing routine questions. During the interview, the participants wrote down $\tan \theta$ even though the formula required $\cos \theta$. Solving problems requires a new and different step or strategy than the steps or strategies in solving routine or usual problems (Kurniawan et al., 2017).

The participants tried to take a test using a procedural approach. They tried to define the problem in a concrete form. These responses were shown in instrument item 4 . This is also found in Egodawatte and Stoilescu's (2015) research that the subject is usually confused with symbols or algebraic forms. A finding from Liberman \& Trope (1998) stated that concrete thought is associated with more feasibility than abstract thought. Individuals who think concretely are more concerned with the course difficulty of the action. They dislike doing something hard, even if it would result in the desired outcome.. In other words, the participants could not tie the vector image into the definition of the resultant vector and modify it in algebraic form. This analysis can be fundamental literature of the way of thinking and learning trajectory of PSMTs. The PSMTs are expected to learn the matter properly and effectively.

\section{Conclusion and Suggestion}

The conceptual and procedural knowledge in this study was classified based on conceptual and procedural knowledge and interpretation into several concepts. Based on interviews and analysis results, the interpretation of several concepts was due to incomplete information, hard 
to choose the right concept, accustomed to routine questions. However, when the questions were modified, the participants did not have the appropriate procedure to solve the questions. Also, the thinking approach was concrete. The participants tried to turn abstract problems into a concrete one. The interpretation of several concepts was unrelated to the questions given in analyzing conceptual and procedural knowledge. It indicated a malfunction in the thinking process of manipulating ideas.

According to the conclusions, the teaching materials' material order had been adjusted to the learning objective. They had a significant contribution in supporting the assimilation and recall process. Also, the question examples chosen were related to the material to improve the conceptual and procedural understanding. A matriculation program or response class is very much needed in content courses, especially Elementary Linear Algebra.

\section{Acknowledgment}

LPPM Universitas Timor supported this study and publication: Research and Community Service Program Grant 2020 Number 29/UN60/LPPM/PP/2020.

\section{References}

Baki, A. (2008). Mathematics teaching from theory to practice. Ankara: Alfa yayınları.

Badjeber, R., \& Mailili, W. H. (2019). Profil Pengetahuan Konseptual Matematis Siswa SMP Ditinjau dari Gaya Kognitif. Anargya: Jurnal Ilmiah Pendidikan Matematika, 2(1), 6-13.

Chen, L., Van Dooren, W., \& Verschaffel, L. (2011). An investigation on Chinese teachers' realistic problem solving abilities and beliefs. Journal of Mathematics Education, 4(2), 8096.

Crespo, S. (2003). Learning to pose mathematical problems: Exploring changes in preservice teachers' practices. Educational Studies in Mathematics, 52, 243-270. https://doi.org/10.1023/A:1024364304664

Dündar, S. (2015). Mathematics Teacher-Candidates' Performance in Solving Problems with Different Representation Styles: The Trigonometry Example. Eurasia Journal of Mathematics, Science, and Technology Education, 11, 1363-1378.

Egodawatte, G., \& Stoilescu, D. (2015). Grade 11 Students' Interconnected Use of Conceptual Knowledge, Procedural Skills, and Strategic Competence in Algebra: A Mixed-Method Study of Error Analysis. European Journal of Science and Mathematics Education, 3(3), 289-305

İşleyen, T., \& Işık, A. (2003). Conceptual and procedural learning in mathematics. Journal of the Korea Society of Mathematical Education (Series D: Research in mathematical education), 7(2), 91-99

Iswanly, F. R., Pomalato, S., \& Djabar, M. A. (2018). Analisis pemahaman konseptual dan kemampuan prosedural matematika ditinjau dari tipe kepribadian siswa di smp negeri 1 pinogaluman. Jurnal Riset Dan Pengembangan Ilmu Pengetahuan, 03, 7-12.

Kadijevich, D. M. (2018). Relating procedural and conceptual knowledge. Teaching of Mathematics, 21(1), 15-28.

Khashan, K.H. (2014). Conceptual and procedural knowledge of rational numbers for Riyadh elementary school teachers. Journal of Education and Human Development, 3(4), 181- 197. 
Kilpatrick, J., Swafford, J. O., \& Findell, B. (2001). Adding it up: Helping Children Learn Mathematics. Washington, DC: National Academy Press

Komarudin. (2016). Analisis Kesalahan Siswa Dalam Pemecahan Masalah Matematika Pada Materi Peluang Berdasarkan High Order Thinking Dan Pemberian Scaffolding. Jurnal Pendidikan, Komunikasi Dan Pemikiran Hukum Islam, VIII(1), 198-213.

Kurniawan, E., Mulyati, S., \& Rahardjo, S. (2017). Proses Asimilasi Dan Akomodasi Dalam. Teori, Penelitian, Dan Pengembangan, 2(5), 592-598.

Liberman, N., \& Trope, Y. (1998). The role of feasibility and desirability considerations in near and distant future decisions: A temporal construal theory test. Journal of Personality and Social Psychology, 75, 5-18.

National Research Council. (2001). Adding it up: Helping Children Learn Mathematics. Washington, DC: National Academy Press

Putri, A. (2018). Analisis Kemampuan Pemecahan Masalah Rutin dan Non-Rutin pada Materi Aturan Pencacahan. Jurnal Pendidikan Tambusai, 2(2), 890-896.

Rittle-Johnson, B. \& Schneider, M. (2012). Developing Conceptual and Procedural Knowledge of Mathematics. In R. Cohen Kadosh \& A. Dowker (Eds.), Oxford handbook of numerical cognition. Oxford University Press.

Schneider, M., \& Stern, E. (2015). The cognitive perspective on learning: Ten cornerstone findings. In Organisation for Economic Co-Operation and Development (OECD) (Ed.), The nature of learning: Using research to inspire practice (pp. 69-90). Paris: OECD. (7) $(P D F)$ The cognitive perspective on learning: Ten cornerstone findings.

Schneider, M., \& Stern, E. (2010). The developmental relations between conceptual and procedural knowledge: A multimethod approach. Developmental Psychology, 46, 178-192. DOI: $10.1037 / \mathrm{a} 0016701$

Smith, S. Z., \& Smith, M. E. (2006). Assessing elementary understanding of multiplication concepts. School Science and Mathematics, 106, 140-148. doi:10.1111/j.19498594.2006.tb18171.x

Star, J. R., Caronongan, P., Foegen, A., Furgeson, J., Keating, B., Larson, M. R., Lyskawa, J., McCallum, W. G., Porath, J., \& Zbiek, R. M. (2015). Teaching strategies for improving algebra knowledge in middle and high school students (NCEE 2014-4333). Washington, DC: National Center for Education Evaluation and Regional Assistance (NCEE), Institute of Education Sciences, U.S. Department of Education. Retrieved from the NCEE website: http://whatworks.ed.gov.

Valanides, N. (2000a). Primary student teachers' understanding of the particulate nature of matter and its transformations during dissolving. Chemistry Education Research and Practice, 1(2), 249-262.. https://doi.org/10.1039/A9RP90026H

Verschaffel, L., Luwel, K., Torbeyns, J., \& Van Dooren, W. (2009). Conceptualizing, investigating, and enhancing adaptive expertise in elementary mathematics education. European Journal of Psychology of Education, 24, 335-359. DOI: 10.1007/bf03174765. 